\title{
A Short Analysis of Biosorbents and its Potential Removal Contaminants from Aqueous Media
}

\author{
Dison S P Franco and Guilherme L Dotto* \\ Chemical Engineering Department, Federal University of Santa Maria-UFSM, Santa Maria, RS, Brazil
}

*Corresponding author: Guilherme L Dotto, Adjunct professor, Chemical Engineering Department, Federal University of Santa Maria-UFSM, Santa Maria, RS, Brazil.

Received Date: May 06, 2020

Published Date: May 13, 2020

Abstract

Biosorbents are materials applied in the sorption process, and are extensively studied throughout the years. Here a brief discussion about the origin of each common biosorbent studied and major characteristics are presented.

Keywords: Characteristics; Biosorbent; Dyes; Heavy metal; Pesticides; Pharmaceuticals

\section{Introduction}

The development of industrial activities led to an increase in the volume of industrial effluents generated. These effluents present a wide variety of organic and inorganic pollutants, such as dyes, heavy metals, pesticides, pharmaceuticals, and aromatic molecules [1-4]. The release of untreated effluents causes serious environmental damage and further public health risk [5].There are several methods for treating these effluents. Some examples are oxidation, electrolysis, ozonation, filtration, reverse osmosis, flocculation/ coagulation, biosorption, microorganisms, and enzymes. Among these techniques, the biosorption is one of the most studied alternatives in the last years, mainly due to its economic aspects and practical application. The biosorption terminology consists of the union of the "bio" prefix and the "sorption" suffix. From a technical point of view mean the application of the adsorption method using materials from biological bias, often called biosorbents.

\section{Biosorbents Characteristics and Classification}

The biosorbent needs to present several characteristics to ensure further employment. The first characteristic is the low-cost and availability, taking into consideration the transport and any modification of the material. To be further applied, the biosorbent need to present chemical and mechanical stability, in special for continuous systems. Significant physicochemical and textural proprieties, in other words, high surface area, pore-volume, and functional groups. These characteristics increase the chances of the higher concentration gradient between the bulk phase and the biosorbent [6]. Although all these characteristics are important for the biosorbent applications, it is difficult to develop a biosorbent with all these features.

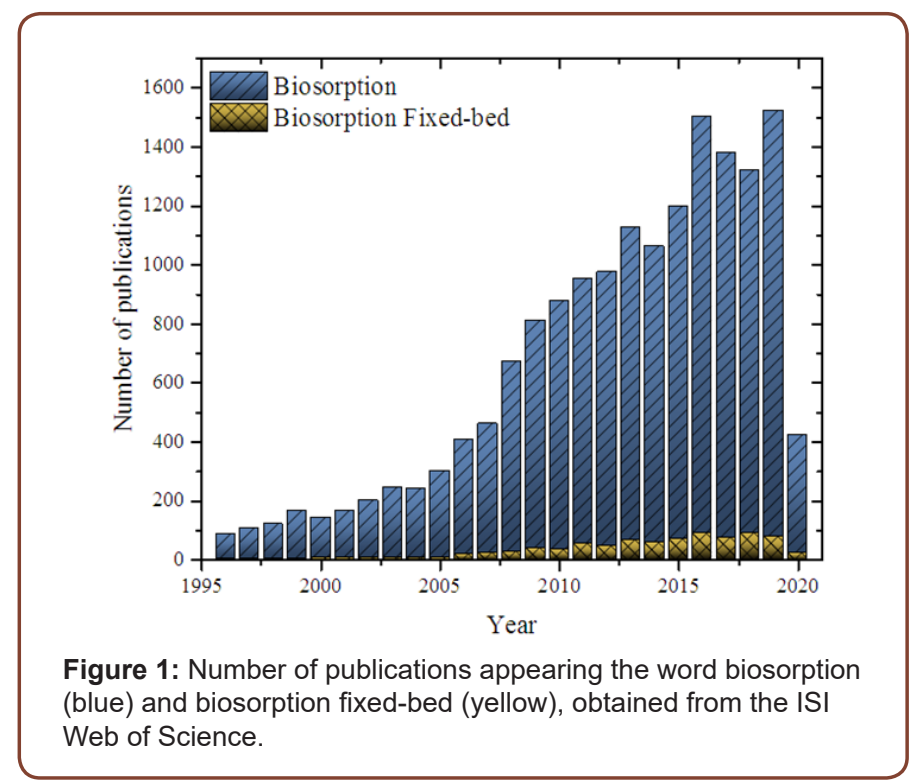


The biosorbents present economic and sustainable benefits. These characteristics have drawn the attention to biosorption studies, where the number of publications doubled in a decade (Figure 1). These studies show several biosorbents developed with different species in the removal of dyes, drugs, pesticides, metals, among others. The latest published articles still bring new materials both in natural and modified to remove pollutants. Still, the lack of fixed-bed biosorption publications is a major concern.

Figure 2 presents the classification for the biosorbents, which is further detailed. The tree bark has been applied for the adsorption of different dyes, such as crystal violet and red $97[7,8]$. The biosorbent from threes often present good biosorption capacity and mechanical stability. Nevertheless, depending on the species, the higher presence of lignin results in lower adsorption capacity. The fruit's seeds are often applied as biosorbents as well for the removal of dyes and heavy metals $(\mathrm{Pb}, \mathrm{Cd}$, and $\mathrm{Zn})[9,10]$.In some cases, the fruits seed present low adsorption performance, due to the presence of oil in the composition. Thus further treatment is welcome. Another material that can be obtained from the wood and agricultural industry is the leaves, for the biosorption of dyes to pharmaceuticals [11]. Generally, the leaves are modified using basic or acid solutions, or used for preparing activated carbon. Other biosorbents are made from the agro-industrial residues are husk and process wastes. Some works have reported the application of activated carbon from rice husk for the removal of ciprofloxacin [12]. Sugar cane and cassava have been modified for the removal of methylene blue [13]. The fruit peel is another often studied, biosorbent group. Similarly, the biosorbent is modified and present low mechanical resistance From the shrimp industry wastes, chitin and chitosan are obtained. These materials are excellent biosorbents, being applied for the removal of dyes, metals, pesticides, pharmaceuticals, and many other compounds [6]. However, chitin and chitosan, similar to other materials, present low mechanical stability. This downside has led to the development of advanced materials such as films, sponge, nanowhiskers, nanoparticles, and nanofibers. Last, the fungi biomass has been reported on the literature as well, e.g., the Bacillus licheniformis was used for the removal of lead [14]. The mainly challenged involving the fungi biomass is related to the fungi production process, which demands time for growth stage.

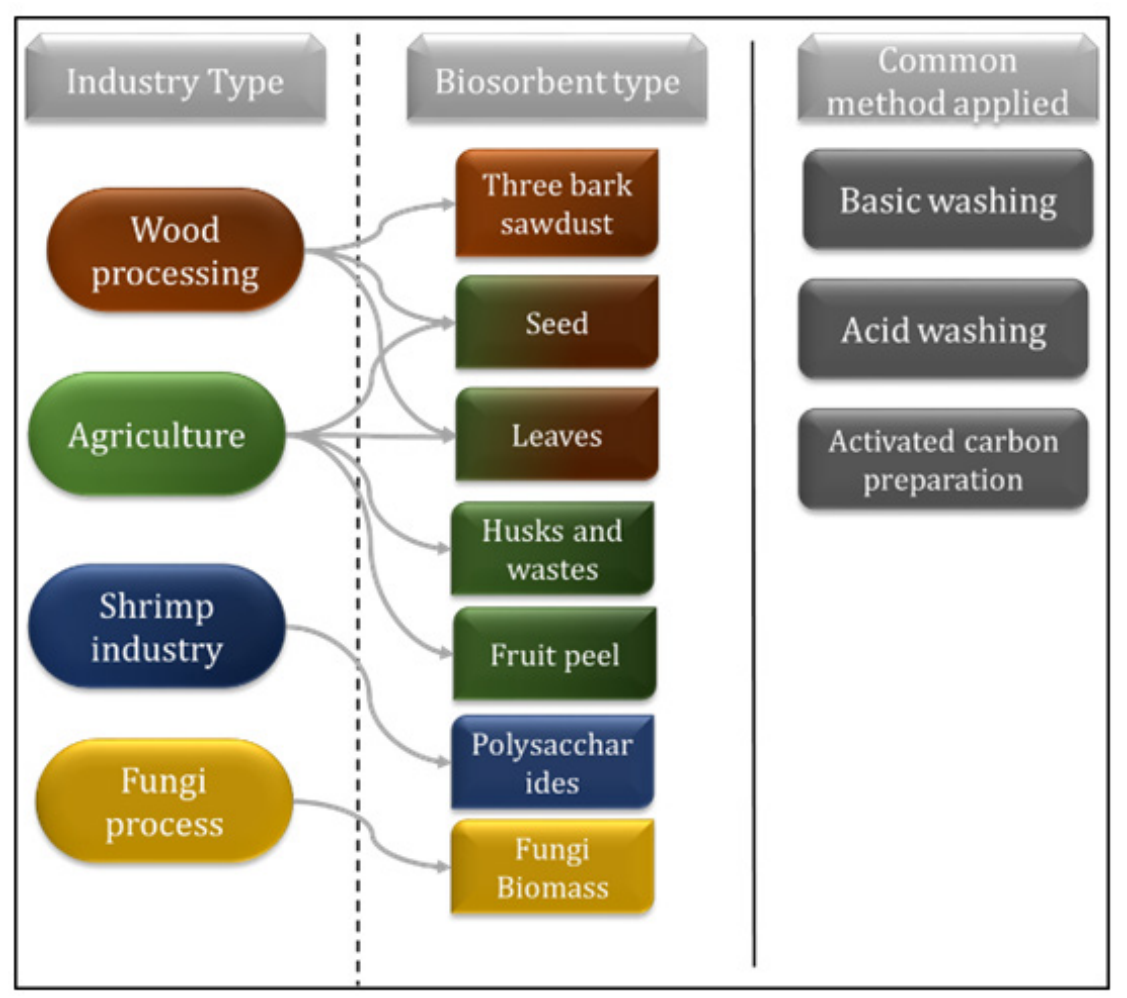

Figure 2: Biosorbent classification according to the industry type.

\section{Conclusion}

In this mini-review, the biosorbent state of the art was presented shortly. The first aspect is that the development of biosorbents has exponentially increased over the years. These materials present a variated biosorption capacity, according to nature and origin. The major characteristics of the biosorbent are related to sustainable and economic characteristics. However, the lack of fixed-bed biosorption reports is a major flaw. Also, the works are mainly focused on the removal of one pollutant per operation. It should be considered the application for mixtures of pollutants to approach real-life effluent conditions. 


\section{Acknowledgment}

None.

\section{Conflict of Interest}

No conflict of interest.

\section{References}

1. G Crini, E Lichtfouse (2018) Green Adsorbents for Pollutant Removal: Innovative materials.

2. T Deblonde, C Cossu Leguille, P Hartemann (2011) Emerging pollutants in wastewater: A review of the literature. Int J Hyg Environ Health 214(6): 442-448.

3. DA Yaseen, M Scholz (2019) Textile dye wastewater characteristics and constituents of synthetic effluents: a critical review. Springer Berlin Heidelberg 16: 1193-1226

4. B Chen, Y Wang, D Hu (2010) Biosorption and biodegradation of polycyclic aromatic hydrocarbons in aqueous solutions by a consortium of white-rot fungi. J Hazard Mater 179(1-3): 845-851.

5. Q Han, J Wang, BA Goodman, J Xie, Z Liu (2020) High adsorption of methylene blue by activated carbon prepared from phosphoric acid treated eucalyptus residue, Powder Technol 366: 239-248.

6. GL Dotto, G McKay (2020) Current scenario and challenges in adsorption for water treatment. J Environ Chem Eng 103988.

7. J Georgin, FC Drumm, P Grassi, D Franco, D Allasia, et al. (2018) Potential of Araucaria angustifolia bark as adsorbent to remove Gentian Violet dye from aqueous effluents. Water Sci Technol 78(8): 1693-1703.
8. J Georgin, DSP Franco, P Grassi, D Tonato, DGA Piccilli, et al, (2019) Potential of Cedrella fissilis bark as an adsorbent for the removal of red 97 dye from aqueous effluents 26(19):19207-19219.

9. DSP Franco, J Georgin, FC Drumm, MS Netto, D Allasia, et al, (2020) Araticum (Annona crassiflora) seed powder (ASP) for the treatment of colored effluents by biosorption. Environ Sci Pollut Res 27: 1118411194.

10. AA Adenuga, OD Amos, JAO Oyekunle, EH Umukoro (2019) Adsorption performance and mechanism of a low-cost biosorbent from spent seedcake of Calophyllum inophyllum in simultaneous cleanup of potentially toxic metals from industrial wastewater. J Environ Chem Eng 7(5): 103317.

11. SN Jain, PR Gogate (2017) Adsorptive removal of acid violet 17 dye from wastewater using biosorbent obtained from $\mathrm{NaOH}$ and $\mathrm{H} 2 \mathrm{SO} 4$ activation of fallen leaves of Ficus racemosa. J Mol Liq 243: 132-143.

12. B Zhang, X Han, P Gu, S Fang, J Bai (2017) Response surface methodology approach for optimization of ciprofloxacin adsorption using activated carbon derived from the residue of desilicated rice husk. J Mol Liq 238: 316-325.

13. AVB de Oliveira, TM Rizzato, BCB Barros, SL Favaro, W Caetano, et al. (2019) Physicochemical modifications of sugarcane and cassava agroindustrial wastes for applications as biosorbents, Bioresour. Technol Reports 7: 100294

14. X Wen, C Du, G Zeng, D Huang, J Zhang, et al. (2018) A novel biosorbent prepared by immobilized Bacillus licheniformis for lead removal from wastewater. Chemosphere 200: 173-179. 